\title{
The Dimensions of Auditory Hallucination in Schizophrenia: Association with Depressive Symptoms and Quality of Life
}

Janaki V ${ }^{\mathrm{a}}$, Suzaily $\mathrm{W}^{\mathrm{a}}$, Abdul Hamid $\mathrm{AR}^{\mathrm{a}}$, Hazli $\mathrm{Z}^{\mathrm{a}}$, Azmawati MN ${ }^{\mathrm{b}}$

${ }^{a}$ Department of Psychiatry, Faculty of Medicine, Universiti Kebangsaan Malaysia Medical Centre, Jalan Yaacob Latiff, Bandar Tun Razak, 56000 Kuala Lumpur, Malaysia

${ }^{b}$ Department of Community Health, Faculty of Medicine, Universiti Kebangsaan Malaysia Medical Centre, Jalan Yaacob Latiff, Bandar Tun Razak, 56000 Kuala Lumpur, Malaysia

\begin{abstract}
Introduction: Auditory hallucination $(\mathrm{AH})$ is often unexplored in depth in clinical practice. This study sought to ascertain the relationship between $\mathrm{AH}$, depressive symptoms and quality of life (QOL) and its association with socio-demographic and clinical variables. Methods: This was a cross sectional study done in a psychiatry unit involving 60 schizophrenic patients between 18 to 60 years old. Psychotic Symptom Rating Scale - Auditory Hallucination subscale (PSYRATS-AH), Calgary Depression Scale for Schizophrenia (CDSS) and World Health Organization Quality of Life-Brief scale (WHOQOL-BREF) were used as instruments. Results: Alcohol intake was found to be significantly associated with the severity of AH. A significant moderate positive correlation was found between AH total score and CDSS $(r=0.53, p<0.001)$ and moderately high correlation between emotional characteristics subscale with CDSS $(r=0.651, p<0.005)$. The PSYRATS-AH dimensions; amount of distress $(r=0.721, p<0.001)$ and intensity of distress $(r=0.757, p<0.001)$ showed significant high correlation with CDSS. As for QOL, frequency of AH $(r=-0.419, p<0.01)$ and CDSS ( $r=-$ $0.435, \mathrm{p}<0.01$ ) showed significant moderate negative correlation, while duration, loudness, amount and intensity of distress, disruption to life and controllability of voices had significant fair correlation with QOL. Multiple regression analysis revealed that the frequency of $\mathrm{AH}(\mathrm{p}=0.047)$, controllability of $\mathrm{AH}(\mathrm{p}=0.027)$ and depressive symptoms $(p=0.001)$ significantly predict QOL. Conclusion: Our results demonstrated that each dimension of $\mathrm{AH}$ had different contributions towards depressive symptoms and the QOL in patients with schizophrenia. Therefore, appropriate treatment focusing on the specific dimension of AH not only may reduce depressive symptoms, but may also improve QOL of these patients.
\end{abstract}

KEYWORDS: auditory hallucination, depressive symptoms, quality of life, schizophrenia

\section{INTRODUCTION}

Schizophrenia is one of the severe psychiatric illnesses that have a median lifetime prevalence of approximately 4.0 per $1000 .^{1}$ The clinical presentation varies from positive to negative symptoms and cognitive impairment as well. Hallucinations were found to be the most common positive symptom in patients with schizophrenia ${ }^{2}$ with auditory hallucination $(\mathrm{AH})$ reported to be the commonest form ${ }^{3}$ having prevalence rate about $64.3 \%$ to $83.4 \% .^{4} \mathrm{AH}$ tends to be frequently persistent despite remission of other psychotic symptoms. Research is still ongoing about $\mathrm{AH}$ to get a better understanding on the neurological process underlying schizophrenia. ${ }^{5}$

Various research had been carried out to look at the consequences of the $\mathrm{AH}$ on the daily living of

Correspondence:

Assoc. Prof. Dr. Suzaily Wahab,

Department of Psychiatry,

Universiti Kebangsaan Malaysia Medical Centre,

Jalan Yaacob Latif, Bandar Tun Razak,

Cheras, 56000 Kuala Lumpur, Malaysia

Tel. No: (603) 91456142

Email: suzailywhb@yahoo.com patients suffering from schizophrenia. A study conducted in Australia involving 199 patients with a psychotic disorder found that depression was common in patients experiencing auditory hallucination. ${ }^{6}$ Another research done in New Zealand in 2010 involving 154 participants which looked into the effects of the content of the auditory hallucination on the emotional well-being found that those who heard voices with negative content were more distressed. ${ }^{7}$ Likewise, similar results were obtained in a research carried out by Daalman et al in 2011 which concluded that commanding or derogative voices cause significant stress that increases the illness burden and therefore affects the quality of life (QOL) in schizophrenia patients. ${ }^{8}$ Commanding $\mathrm{AH}$ was also reported to increase the suicidal attempt especially in schizophrenia patients who had a past history of attempting suicide. ' Hence, the presence of $\mathrm{AH}$ especially those with negative and critical comments undoubtedly has an impact on the emotional well-being as well as the QOL in schizophrenia patients.

The available local studies focused more on examining QOL and depressive symptoms in schizophrenia patients but to our knowledge no local study had been done focusing on the 
characteristics of $\mathrm{AH}$ in schizophrenia patients. A local research involving 206 patients with schizophrenia looking into their QOL found that general psychopathology and depressive symptoms had a significant association with subjective QOL. ${ }^{10}$ Another Malaysian study reported that the QOL was generally poor in community based schizophrenia patients. $^{11}$

So far, there had been a number of research being done that linked positive and negative symptoms of schizophrenia with QOL. ${ }^{12,13}$ Available assessment tools for instance Positive and Negative Syndrome Scale (PANSS) measures a broad range of symptoms in a single dimensional scale and it is not specific to AH per se. ${ }^{14}$ Haddock et al (1999) argued regarding the need of using scales that could assess the dimensions of hallucinations and delusions to further explore the psychological process behind symptom expression. ${ }^{15}$ She also pointed out the importance of understanding the change in each dimension to tailor the specific treatment needs in each patient. Realizing the importance of understanding the multidimensional components of $\mathrm{AH}$, our study seeks to determine the relationship between $\mathrm{AH}$, depressive symptoms and QOL of schizophrenia patients and its association with socio-demographic and clinical variables.

\section{MATERIALS \& METHODS}

\section{Participants and procedure}

Simple random sampling method was utilised in this cross sectional study to determine the relationship between $\mathrm{AH}$, depressive symptoms and $\mathrm{QOL}$ in patients with schizophrenia. The study participants recruited were patients from the psychiatric unit of Universiti Kebangsaan Malaysia Medical Centre (UKMMC) whom were diagnosed with schizophrenia. The recruitment was done over a period of 6 months from December 2015 until May 2016. The inclusion criteria was patients whom fulfilled the DSM 5 criteria for schizophrenia, aged between 18 to 60 years, not severely psychotic determined by Brief Psychiatric Rating Scale (BPRS) score of $<52^{16}$, able to give written consent and those who are able to understand as well as communicate either in Malay or English.

Patients whom were not keen to participate, having other DSM 5 diagnosis, severely psychotic or mentally retarded and having comorbid substance abuse were excluded. Consent was also taken from patients' relative. The ethical committee of Pusat Perubatan Universiti Kebangsaan Malaysia (PPUKM) had granted approval for this research.

The sample size was calculated based on weak correlation of Psychotic Symptom Rating Scale, AH domain (PSYRATS-AH) ${ }^{17}$ utilising $\mathrm{G}$ power software $\left(R^{2}=0.375,2\right.$ tail study, power $80 \%$, a 0.05$)$.

\section{Instruments}

Socio-demographic questionnaire was used to gather particulars about the socio-demographic as well as clinical variables of the participants that could be related with the study outcome. These included age, sex, race, marital status, education level, employment status, age of onset of illness, duration of hearing voices, diagnosis, medication type, smoking, history of substance or alcohol intake and medical illness. Information was obtained through interview and the available medical records.

Mini International Neuropsychiatric Interview (M.I.N.I) 6.0 module K (psychotic disorder) was used for confirmation of diagnosis of schizophrenia. ${ }^{18}$ It is a short structured, brief diagnostic tool for current as well as lifetime DSM-5 and ICD-10 psychiatric disorders. ${ }^{18}$ The M.I.N.I has good validity and reliability and has been translated into many different languages. ${ }^{18}$ The translated Malay version was used in this study.

Brief Psychiatric Rating Scale (BPRS) was utilised to assess the severity of schizophrenia symptoms. It is an interviewer administered assessment tool, consisting of 18 items. ${ }^{19}$ Patients with scores above 52 are regarded as markedly ill $^{16}$ and therefore were excluded from the study.

The severity of $\mathrm{AH}$ was assessed using the Psychotic Symptom Rating Scales, auditory hallucination domain (PSYRATS-AH). PSYRATS is an interviewerrated, 17 items, 5-point scale measuring the severity of auditory hallucination and delusion over the past one week. PSYRATS-AH consists of 11 items/dimensions "(frequency, duration, location, loudness, beliefs regarding origin of voice, amount of negative content, intensity of negative content, amount of distress, intensity of distress, disruption to life and controllability)". These items can be further grouped into physical characteristics (frequency, duration, location and loudness), emotional characteristics (amount and degree of negative content, amount and intensity of distress) and cognitive interpretation (beliefs regarding origin of voice, disruption to life and controllability). ${ }^{15}$ Each item is evaluated on a point scale with a minimum score of zero (absent) to a maximum score of four (severe). Higher score indicates greater severity of symptoms. The maximum total score is 44. The validated Malay version (MyPSYRATS), ${ }^{20}$ was used in this study. MyPSYRATS has been shown to have good psychometric properties with the Cronbach's alpha value of 0.86 .

The presence of depressive symptoms in schizophrenia patients was assessed utilising the Calgary Depression Scale for Schizophrenia (CDSS). There were 9 items in this questionnaire; interviewer-rated on a 4-point scale with a cut-off score of $>6$ points indicated the presence of depressive symptoms. ${ }^{21}$ CDSS was used globally in the assessment of depressive symptoms in 
schizophrenia patients and it has shown to have good psychometric properties. ${ }^{22}$ The translated Malay version was used in this study.

World Health Organization Quality of Life-Brief (WHOQOL-BREF) was administered to assess the overall QOL in the studied patients. WHOQOL-BREF comprised of 26 items on a 5-point scale with 4 domains namely "physical (7 items), psychological (6 items), social relationship (3 items) and environmental domain ( 8 items)" and 2 items on overall QOL. ${ }^{23}$ Higher scores denoted a better QOL. It has been validated in the Malay language as well with satisfactory psychometric properties. ${ }^{24}$ The validated Malay version was used in this study.

\section{Statistical analysis}

Data entry as well as statistical analysis was carried out utilising Statistical Package for Social Sciences (SPSS) version 23. Descriptive analysis was done using means and standard deviation (SD) for continuous variables whereas frequencies (\%) were used for categorical variables. Bivariate analysis was performed with either independant $t$ test or one way analysis of variance (ANOVA) for the analysis of association between sociodemographic and clinical factors with $\mathrm{AH}$ and QOL. Depressive symptoms which was a non-normally distributed data was analysed descriptively using median and interquartile range. Pearson and Spearman correlation was used for the analysis of association between auditory hallucination, depressive symptoms and quality of life. Simple linear regression was done to determine the linear association of each independant variable to dependant variable $(\mathrm{QOL})$. This was followed by multiple linear regression analysis to determine the factors that predict QOL.

\section{RESULTS}

\section{Sociodemographic and clinical characteristics}

A total of 60 participants who met the research criteria specified were recruited into the study within the duration of 6 months. Table I shows the sociodemographic and clinical characteristics of the respondents. The mean age was noted to be 39.68 $(\mathrm{SD}=9.40)$. In terms of gender, it was almost equal in number, males were $33(55 \%)$ and females 27 (45\%). Majority of the patients were Chinese, 32 (53.3\%); unemployed, 46 (76.7\%); single, $43(71.7 \%)$ and with a lower educational background, 40 (66.7\%).

The mean age of onset of illness was 25 (SD=7.81) years old and the mean duration of hearing voices was 14.70 ( $S D=9.38$ ) years. About one third, 21 (35\%) of the patients were classified as treatment resistant schizophrenia (TRS). The mean of total number of voices heard was $4.93 \quad(S D=3.95)$ with predominantly second $(91.7 \%)$ and third $(88.3 \%)$ person $\mathrm{AH}$. Besides $\mathrm{AH}, 43.3 \%$ of the patients experienced visual hallucinations as well. Majority of them were on atypical antipsychotics (66.7\%). Almost two third $(65 \%)$ of the patients were smokers; majority of them (88.3\%) did not have any history of substance abuse or alcohol intake and 73.7\% had no comorbid medical illness.

\section{Clinical outcome characteristics}

The overall mean score for PSYRATS-AH was 27 $(S D=5.92)$. The physical characteristics contributed to the highest mean score of $9.82 \quad(S D=2.38)$, followed by emotional characteristics which was 8.87 ( $\mathrm{SD}=3.87)$ and cognitive interpretation 8.32 $(S D=2.12)$ respectively. CDSS total mean score was $6.42(S D=5.08)$. The percentage of patients who were found to be depressed as compared to nondepressed were equal (50\%). The mean score for WHOQOL-BREF (total domains) was 62.97 $(S D=11.58)$. The physical domain had the highest mean score of $51.13 \quad(S D=13.86)$ whereas social domain had the least mean score of 41.11 $(S D=16.94)$.

Table II shows the association between sociodemographic and clinical characteristics of the patients with severity of $\mathrm{AH}$ and QOL. Patients with alcohol intake as compared to patients without any history of substance or alcohol showed significant association with the severity of $\mathrm{AH}(\mathrm{p}<0.05)$. There was no significant association between all the sociodemographic and clinical variables studied with depressive symptoms and QOL.

\section{Correlations between PSYRATS-AH, CDSS and WHOQOL-BREF}

Table III shows the correlation between auditory hallucination score (PSYRATS-AH) with depressive symptoms (CDSS) and QOL (WHOQOL-BREF). A significant moderate positive correlation was found between AH total score and CDSS $(r=0.53, p<0.001)$ and moderately high correlation between emotional characteristics subscale with CDSS $(r=0.651$, $\mathrm{p}<0.005)$. With regards to the correlation between the 11 items/dimensions in PSYRATS-AH with CDSS, the amount of distress $(r=0.721, \quad p<0.001)$ and intensity of distress $(r=0.757, p<0.001)$ showed significant high correlation. The- correlation between amount of negative content with CDSS was fair $(r=0.372, p<0.01)$ while it was poor for duration $(r=0.272, p<0.05)$. A significant moderate negative correlation was found between $\mathrm{AH}$ total score, physical characteristics subscale and depressive symptoms with QOL with $r$ value of -0.496 $(p<0.001), \quad-0.472 \quad(p<0.001)$ and $-0.435 \quad(p<0.01)$ respectively. Cognitive interpretation subscale had fair correlation $(r=-0.381, p<0.01)$ with QOL. With respect to the association of the 11 items/ dimensions of PSYRATS-AH with QOL (Table III), frequency $(r=-0.419, p<0.01)$ was found to have a significant moderate negative correlation with QOL while duration $(r=-0.360, \quad p<0.01)$, loudness $(r=-$ $0.328, \quad p<0.01)$, amount of distress $(r=-0.330$, $p<0.05)$, intensity of distress $(r=-0.347, p<0.01)$, disruption to life $(r=-0.363, \quad p<0.01)$ and controllability $(r=-0.399, p<0.01)$ had significant fair correlation with QOL. 


\section{Factors predicting QOL}

As shown in Table IV, simple linear regression analysis was initially carried out to determine the possible factors that were related with QOL. History of alcohol intake, depressive symptoms (CDSS), PSYRATS-AH items/dimensions namely frequency, duration, loudness, amount and intensity of distress, disruption to life and controllability of voices were the significant factors associated with QOL. Multiple regression analysis using the forward model was further performed to control for confounder effects and to ascertain the significant factors that predicted QOL. The significant factors of PSYRATS$\mathrm{AH}$ items which predicted $\mathrm{QOL}$ were frequency $(p=0.047)$, and controllability of the voices $(p=0.027)$. CDSS score for depressive symptoms was also notably significant $(p=0.001)$ as a predictor of QOL.

Table I Sociodemographic and clinical characteristics of respondents $(n=60)$

\begin{tabular}{|c|c|c|}
\hline Variables & Mean(SD) & $\mathrm{n}(\%)$ \\
\hline Age & $39.68(9.40)$ & \\
\hline \multicolumn{3}{|l|}{ Gender } \\
\hline Male & & $33(55.0)$ \\
\hline Female & & $27(45.0)$ \\
\hline \multicolumn{3}{|l|}{ Race } \\
\hline Malay & & $22(36.7)$ \\
\hline Chinese & & $32(53.3)$ \\
\hline Indian & & $6(10.0)$ \\
\hline \multicolumn{3}{|l|}{ Marital status } \\
\hline Single & & $43(71.7)$ \\
\hline Married & & $8(13.3)$ \\
\hline Divorced & & $9(15.0)$ \\
\hline \multicolumn{3}{|l|}{ Education Level } \\
\hline Lower $^{a}$ & & $40(66.7)$ \\
\hline Higher $^{\mathrm{b}}$ & & $20(33.3)$ \\
\hline \multicolumn{3}{|l|}{ Employment status } \\
\hline Employed & & $14(23.3)$ \\
\hline Unemployed & & $46(76.7)$ \\
\hline Age of onset of illness & $25.00(7.81)$ & \\
\hline $\begin{array}{l}\text { Duration of hearing } \\
\text { voices (year) }\end{array}$ & $14.70(9.38)$ & \\
\hline Total number of voices & $4.93(3.95)$ & \\
\hline \multicolumn{3}{|l|}{ Form of voices } \\
\hline $1^{\text {st }}$ person & & $1(1.7)$ \\
\hline $2^{\text {nd }}$ person & & $55(91.7)$ \\
\hline $3^{\text {rd }}$ person & & $3(88.3)$ \\
\hline Single word & & $4(6.7)$ \\
\hline \multicolumn{3}{|l|}{ Other forms of hallucination } \\
\hline Visual & & $26(43.3)$ \\
\hline Tactile & & $11(18.3)$ \\
\hline Olfactory & & $7(11.7)$ \\
\hline \multicolumn{3}{|l|}{ Diagnosis } \\
\hline Schizophrenia & & $39(65.0)$ \\
\hline Treatment resistant Schizophrenia(TRS) & & $21(35.0)$ \\
\hline \multicolumn{3}{|l|}{ Medication type (antipsychotic) } \\
\hline Typical & & $6(10.0)$ \\
\hline Atypical & & $40(66.7)$ \\
\hline Combination & & $14(23.3)$ \\
\hline \multicolumn{3}{|l|}{ Smoker } \\
\hline Yes & & $21(35.0)$ \\
\hline No & & $39(65.0)$ \\
\hline \multicolumn{3}{|l|}{ History of substance/alcohol intake } \\
\hline Substance & & $2(3.3)$ \\
\hline Alcohol & & $5(8.3)$ \\
\hline No & & $53(88.3)$ \\
\hline \multicolumn{3}{|l|}{ Medical illness } \\
\hline Yes & & $14(23.3)$ \\
\hline No & & $46(76.7)$ \\
\hline
\end{tabular}

$\mathrm{n}=$ Number of respondents, \%=Percentage, SD=Standard deviation 
Table II Sociodemographic and clinical characteristics with severity of auditory hallucination and quality of life

\begin{tabular}{|c|c|c|c|c|c|c|}
\hline \multirow[b]{2}{*}{ Variables } & \multicolumn{3}{|c|}{ Auditory hallucination } & \multicolumn{3}{|c|}{ Quality of life } \\
\hline & Mean (SD) & Statistical test & $\mathrm{p}$-value & Mean (SD) & Statistical test & $\mathrm{p}$-value \\
\hline Age & $39.68(9.40)$ & $0.009^{a}$ & 0.948 & $39.68(9.40)$ & $-0.090^{\mathrm{a}}$ & 0.496 \\
\hline $\begin{array}{l}\text { Gender } \\
\text { Male } \\
\text { Female }\end{array}$ & $\begin{array}{l}26.33(6.01) \\
27.81(5.82)\end{array}$ & $-0.964^{\mathrm{b}}$ & 0.339 & $\begin{array}{l}73.85(12.26) \\
73.96(14.69)\end{array}$ & $-0.033^{b}$ & 0.974 \\
\hline $\begin{array}{l}\text { Race } \\
\text { Malay } \\
\text { Non-Malay }\end{array}$ & $\begin{array}{l}27.50(6.91) \\
26.71(5.35)\end{array}$ & $0.495^{\mathrm{b}}$ & 0.623 & $\begin{array}{l}75.68(13.31) \\
72.87(13.34)\end{array}$ & $0.788^{b}$ & 0.434 \\
\hline $\begin{array}{l}\text { Marital status } \\
\text { Single } \\
\text { Married } \\
\text { Divorced }\end{array}$ & $\begin{array}{l}26.21(6.05) \\
27.13(4.94) \\
30.67(5.17)\end{array}$ & $2.197^{c}$ & 0.120 & $\begin{array}{l}74.98(11.89) \\
77.88(13.76) \\
65.22(16.96)\end{array}$ & $2.546^{c}$ & 0.087 \\
\hline $\begin{array}{l}\text { Education Level } \\
\text { Lower } \\
\text { Higher }\end{array}$ & $\begin{array}{l}27.18(5.76) \\
26.65(6.38)\end{array}$ & $0.321^{b}$ & 0.749 & $\begin{array}{l}71.68(12.82) \\
78.35(13.39)\end{array}$ & $-1.873^{b}$ & 0.066 \\
\hline $\begin{array}{l}\text { Employment status } \\
\text { Employed } \\
\text { Unemployed }\end{array}$ & $\begin{array}{l}26.21(5.95) \\
27.23(5.96)\end{array}$ & $-0.564^{b}$ & 0.575 & $\begin{array}{l}75.21(13.22) \\
73.50(13.24)\end{array}$ & $0.420^{\mathrm{b}}$ & 0.676 \\
\hline Age of onset of illness & $25.00(7.18)$ & $-0.078^{\mathrm{a}}$ & 0.555 & $25.00(7.18)$ & $-0.008^{\mathrm{a}}$ & 0.951 \\
\hline $\begin{array}{l}\text { Duration of hearing } \\
\text { voices (year) }\end{array}$ & $14.70(9.38)$ & $0.070^{\mathrm{a}}$ & 0.594 & $14.70(9.38)$ & $-0.086^{a}$ & 0.511 \\
\hline $\begin{array}{l}\text { Diagnosis } \\
\text { Schizophrenia } \\
\text { Treatment Resistant } \\
\text { Schizophrenia(TRS) }\end{array}$ & $\begin{array}{l}26.44(5.75) \\
28.05(6.23)\end{array}$ & $-1.006^{\mathrm{b}}$ & 0.319 & $\begin{array}{l}76.18(12.15) \\
69.67(14.54)\end{array}$ & $1.848^{\mathrm{b}}$ & 0.070 \\
\hline $\begin{array}{l}\text { Medication type } \\
\text { Typical antipsychotic } \\
\text { Atypical antipsychotic } \\
\text { Combination }\end{array}$ & $\begin{array}{l}23.16(7.44) \\
27.33(5.15) \\
27.71(7.12)\end{array}$ & $1.441^{\mathrm{c}}$ & 0.245 & $\begin{array}{l}77.00(10.60) \\
74.05(13.85) \\
72.14(13.20)\end{array}$ & $0.281^{c}$ & 0.756 \\
\hline $\begin{array}{l}\text { Smoker } \\
\text { Yes } \\
\text { No }\end{array}$ & $\begin{array}{l}26.76(6.06) \\
27.13(5.92)\end{array}$ & $-0.227^{\mathrm{b}}$ & 0.821 & $\begin{array}{l}70.95(10.32) \\
75.49(14.51)\end{array}$ & $-1.268^{b}$ & 0.210 \\
\hline $\begin{array}{l}\text { History of substance/ } \\
\text { alcohol intake } \\
\text { Substance } \\
\text { Alcohol } \\
\text { No }\end{array}$ & $\begin{array}{l}24.00(9.90) \\
33.00(5.20) \\
26.55(5.64)\end{array}$ & $3.202^{c}$ & $0.048^{* d}$ & $\begin{array}{l}65.50(2.12) \\
62.40(9.02) \\
75.30(13.28)\end{array}$ & $2.718^{c}$ & 0.075 \\
\hline $\begin{array}{l}\text { Medical illness } \\
\text { Yes } \\
\text { No }\end{array}$ & $\begin{array}{l}27.50(7.37) \\
26.85(5.49)\end{array}$ & $0.358^{\mathrm{b}}$ & 0.721 & $\begin{array}{l}70.36(17.65) \\
74.98(11.67)\end{array}$ & $-0.920^{\mathrm{b}}$ & 0.371 \\
\hline
\end{tabular}

$\mathrm{a}=$ Pearson correlation $(\mathrm{r}),{ }^{*} \mathrm{p}<0.05$ significant

$\mathrm{b}=\mathrm{t}$-test

$\mathrm{c}=$ One way ANOVA

$\mathrm{d}=$ post hoc test - alcohol intake vs no alcohol/substance

intake differ significantly 
Table III Correlation between auditory hallucination (PSYRATS-AH) total, subgroups and items; depressive symptoms (CDSS) and quality of life (WHOQOL-BREF)

\begin{tabular}{|c|c|c|c|c|}
\hline & \multicolumn{2}{|c|}{ Depressive symptom (CDSS) } & \multicolumn{2}{|c|}{ Quality of life (WHOQOL-BREF) } \\
\hline & Spearman correlation, $r$ & p-value & Pearson correlation, $r$ & $\mathrm{p}$-value \\
\hline Auditory hallucination (Total) & 0.530 & $<0.001^{* * *}$ & -0.496 & $<0.001^{* * *}$ \\
\hline Emotional characteristics & 0.651 & $<0.001^{* * *}$ & -0.261 & $0.044^{*}$ \\
\hline Cognitive interpretation & 0.024 & 0.857 & -0.381 & $0.003^{* *}$ \\
\hline Physical characteristics & 0.238 & 0.067 & -0.472 & $<0.001^{* * *}$ \\
\hline $\begin{array}{l}\text { Depressive symptoms } \\
\text { (total CDSS score) }\end{array}$ & & & -0.435 & $0.001^{* *}$ \\
\hline $\begin{array}{l}\text { Auditory hallucination } \\
\text { (PSYRATS-AH) items }\end{array}$ & & & & \\
\hline Frequency & 0.148 & 0.260 & -0.419 & $0.001^{* *}$ \\
\hline Duration & 0.272 & $0.036^{*}$ & -0.360 & $0.005^{* *}$ \\
\hline Location & -0.096 & 0.464 & -0.071 & 0.588 \\
\hline Loudness & 0.242 & 0.063 & -0.328 & $0.011^{*}$ \\
\hline Origin of voice & -0.187 & 0.152 & -0.108 & 0.413 \\
\hline Amount of negative content & 0.372 & $0.003^{* *}$ & -0.124 & 0.345 \\
\hline Degree of negative content & 0.250 & 0.054 & -0.040 & 0.763 \\
\hline Amount of distress & 0.721 & $<0.001^{* * *}$ & -0.330 & $0.010^{*}$ \\
\hline Intensity of distress & 0.757 & $<0.001^{* * *}$ & -0.347 & $0.007^{* *}$ \\
\hline Disruption to life & 0.348 & $0.006^{* *}$ & -0.363 & $0.004^{* *}$ \\
\hline Controllability & 0.060 & 0.649 & -0.399 & $0.002^{* *}$ \\
\hline
\end{tabular}

${ }^{*} \mathrm{p}<0.05 \quad{ }^{* *} \mathrm{p}<0.01 \quad{ }^{* * *} \mathrm{p}<0.001$

\section{DISCUSSION}

This cross sectional study looked into the relationship between $\mathrm{AH}$, depressive symptoms and QOL in patients with schizophrenia as well as the socio-demographic and clinical variables that were associated. The mean age of onset of illness in this study was 25 years old with the patients' predominantly experiencing $2^{\text {nd }}$ and $3^{\text {rd }}$ person $\mathrm{AH}$. The mean duration of hearing voices was found to be 15 years. Our findings were in keeping with previous studies which reported that the usual age of onset of illness is either in the late teens or early twenties..$^{25,26}$ In our study, socio-demographic factors such as gender, ethnicity, marital, employment and education status did not show significant association with either $\mathrm{AH}$, depressive symptoms or QOL. Similar findings of no significant association were obtained in a few studies exploring the relationship between socio-demographic factors with QOL. ${ }^{10,27,28}$ On the other hand, there were studies that reported employment status had a significant positive association with QOL. ${ }^{29}$ whereas those unemployed had a poor QOL. ${ }^{30}$ Nevertheless, a number of factors such as socio-cultural and ethnicity differences ${ }^{31}$, study design and settings as well as the assessment tools that were used to measure the outcome might have contributed to the difference in findings.

Among the clinical variables studied, history of alcohol intake showed significant association with severity of auditory hallucination. Our findings were in keeping with previous studies which had shown significant association between positive symptoms and alcohol use. ${ }^{32,33}$ In this study, one third of the patients enrolled were treatment-resistant schizophrenia (TRS). Studies have shown that the more severe the illness is, the more severe $\mathrm{AH}$ or positive symptoms are generally expected. ${ }^{34,35}$ Surprisingly, no significant association was found in terms of severity of $\mathrm{AH}$, depressive symptoms or QOL with the diagnosis of TRS or non TRS patients. These findings could possibly have been contributed by a number of variables not explored in this study, such as the compliance to antipsychotics, coping strategies towards the $\mathrm{AH}$ or insight about the illness, which could affect the study outcome. The anti depressant effect of clozapine could be another factor as well that might have played a part in the insignificance findings between the TRS and non TRS patients.

In this study, $50 \%$ of the patients suffered from depressive symptoms in relation to the presence of auditory hallucination. Similar findings were also reported in earlier studies exploring auditory hallucination and the relationship with depression in 
Table IV Simple and multiple linear regression analysis of factors predicting QOL

\begin{tabular}{|c|c|c|c|c|c|c|}
\hline & & & QOL (WHOQOL & & & \\
\hline & Crude B & $p$-value & $95 \% \mathrm{Cl}$ & Adjusted $\mathrm{B}^{\mathrm{a}}$ & $\mathrm{p}$-value & $95 \% \mathrm{Cl}$ \\
\hline Age & -0.13 & 0.496 & $-0.50,0.24$ & & & \\
\hline $\begin{array}{l}\text { Gender } \\
\text { (female vs male) }\end{array}$ & 0.11 & 0.974 & $-6.85,7.08$ & & & \\
\hline $\begin{array}{l}\text { Race } \\
\text { (Non-Malay vs Malay) }\end{array}$ & -2.81 & 0.434 & $-9.96,4.33$ & & & \\
\hline $\begin{array}{l}\text { Marital status } \\
\text { (single/divorced vs married) }\end{array}$ & -4.59 & 0.368 & $-14.70,5.53$ & & & \\
\hline $\begin{array}{l}\text { Education level } \\
\text { (lower vs higher) }\end{array}$ & -6.68 & 0.066 & $-13.81,0.46$ & & & \\
\hline $\begin{array}{l}\text { Employment status } \\
\text { (unemployed vs employed) }\end{array}$ & -1.71 & 0.676 & $-9.89,6.46$ & & & \\
\hline Age of onset of illness & -0.01 & 0.951 & $-0.50,0.47$ & & & \\
\hline $\begin{array}{l}\text { Duration of hearing voices } \\
\text { (years) }\end{array}$ & -0.12 & 0.511 & $-0.49,0.25$ & & & \\
\hline $\begin{array}{l}\text { Diagnosis } \\
\text { (TRS vs schizophrenia) }\end{array}$ & -6.51 & 0.070 & $-13.57,0.54$ & & & \\
\hline $\begin{array}{l}\text { Smoking } \\
\text { (smoker vs non-smoker) }\end{array}$ & -4.54 & 0.210 & $-11.70,2.63$ & & & \\
\hline $\begin{array}{l}\text { History of substance/alcohol } \\
\text { intake } \\
\text { (intake vs no intake) }\end{array}$ & -12.48 & $0.028^{*}$ & $-23.55,-1.42$ & & & \\
\hline $\begin{array}{l}\text { Medical illness } \\
\text { (illness vs no illness) }\end{array}$ & -4.62 & 0.258 & $-12.72,3.48$ & & & \\
\hline $\begin{array}{l}\text { Auditory hallucination } \\
\text { (PSYRATS-AH) items }\end{array}$ & & & & & & \\
\hline Frequency & -5.25 & $0.001^{*}$ & $-8.24,-2.26$ & -3.04 & 0.047 & $-6.03,-0.05$ \\
\hline Duration & -4.50 & $0.005^{*}$ & $-7.57,-1.43$ & & & \\
\hline Location & -1.46 & 0.588 & $-6.83,3.91$ & & & \\
\hline Loudness & -5.76 & $0.011^{*}$ & $-10.13,-1.39$ & & & \\
\hline Origin of voice & -1.11 & 0.413 & $-3.81,-1.59$ & & & \\
\hline Amount of negative content & -1.45 & 0.345 & $-4.49,1.60$ & & & \\
\hline Degree of negative content & -0.43 & 0.763 & $-3.24,2.39$ & & & \\
\hline Amount of distress & -3.45 & $0.010^{*}$ & $-6.05,-0.86$ & & & \\
\hline Intensity of distress & -3.99 & $0.007^{*}$ & $-6.83,-1.15$ & & & \\
\hline Disruption to life & -7.41 & $0.004^{*}$ & $-12.41,-2.41$ & & & \\
\hline Controllability & -4.89 & $0.002^{*}$ & $-7.84,-1.94$ & -3.28 & 0.027 & $-6.12,-0.38$ \\
\hline $\begin{array}{l}\text { Depressive symptoms } \\
\text { (total CDSS score) }\end{array}$ & -1.14 & $0.001^{*}$ & $-1.76,-0.52$ & -1.00 & 0.001 & $-1.56,-0.44$ \\
\hline
\end{tabular}

$\mathrm{a}=$ forward model regression analysis 
schizophrenia patients. ${ }^{26,36,37}$ We also found a significant positive correlation between severity of $\mathrm{AH}$ with depressive symptoms. When the components of $\mathrm{AH}$ were analysed, the amount of distress and intensity of distress due to the voices heard having the strongest correlation with depression in the population studied. Our results did not support the earlier findings of Soppitt and Birchwood $(1997)^{37}$, who reported that the content of the voices, especially derogatory content $(p=0.0004)$, intrusiveness and loudness of the voice as well as malevolent beliefs were the factors associated to the development of depression in schizophrenia patients. Amount of negative content showed significant fair correlation with depressive symptoms but degree of negative content surprisingly had no correlation in this study. This was in contrary to another study which found both amount and degree of negative content having no significant correlation with depressive symptoms. ${ }^{26}$

With regards to QOL, there was an inverse significant relationship with severity of auditory hallucination. Mainly, the physical characteristics of the voices, cognitive interpretation and to an extent the emotional characteristics (amount and intensity of distress) had significant fair negative correlation with QOL. These findings were partially in line with a study that found commanding derogatory voices imposing great distress and therefore reducing the QOL in patients with psychotic disorders. ${ }^{8}$ Other studies were more focused on positive symptoms as a whole in relation to $\mathrm{QOL}$ rather than looking into the $\mathrm{AH}$ component which is multidimensional. Caron et al $(2005)^{38}$ found a negative association between positive symptoms severity with QOL. Likewise, in a meta-analysis conducted by Eack and Newhill (2007) ${ }^{39}$ on 56 studies exploring the association between psychiatric symptoms and QOL in patients with schizophrenia, it was demonstrated that there was a significant moderate negative association between positive as well as negative symptoms with QOL, whereas the association of QOL with general psychopathology showed consistent inverse relationship in all research sample and treatment settings. Another pooled analysis also reported that patients with less psychiatric symptoms had a better QOL. ${ }^{40}$ Nevertheless, few authors found that there were no significant association between positive symptoms and QOL. ${ }^{41,42}$

Depressive symptoms were found to have a significant moderate negative correlation with QOL. This finding was in fact consistent with several researches done formerly looking into the relationship between depressive symptoms and QOL. ${ }^{10,27}$ Depressive symptoms also constituted one of the important and strongest factors predicting QOL in the final model of regression analysis which was supported by other studies as well. ${ }^{10,28,43}$ The "distress/protection model" of $\mathrm{QOL}^{44}$ shall be used to explain this finding. Based on this model, if there is a predomination of distressing factors (e.g. depressive symptoms) over protective factors (e.g. social support, self esteem) this could result in the reduction of one or more $\mathrm{QOL}$ domain score. In this study, in relation to $\mathrm{AH}$ items, frequency and controllability of voices were found to predict QOL whereby an increase in the frequency of the $\mathrm{AH}$ and an increase in the uncontrollability of $\mathrm{AH}$ will decrease QOL score by 3 times resulting in poorer $\mathrm{QOL}$. The literature pertaining to $\mathrm{AH}$ items as predictor of QOL are scarce. Former studies have found that positive symptoms severity in general predicted poor QOL. ${ }^{45,46}$ Possible factors that could have contributed to persistent $\mathrm{AH}$ could partly be due to patients' belief regarding the uncontrollability of voices itself, coping mechanisms adopted as well as low self esteem. These factors gave rise to depression ${ }^{47}$ which ultimately affects the QOL.

There were several limitations in this current study. The recruitment of participants from only one tertiary centre may not be representative of schizophrenia patients collectively and may impede generalization of our findings. The longitudinal relationship between the variables and outcome studied also could not be established due to the cross sectional study method. Further studies in this area may benefit from a prospective approach involving participants from randomly selected centres in the country.

\section{CONCLUSION}

Despite its limitations, this study had highlighted the need to properly assess each of the multidimensional components of $\mathrm{AH}$, as each component showed different contribution to the presence of depressive symptoms and the QOL in the patients. The frequency of the $\mathrm{AH}$ and the perceived controllability of the $\mathrm{AH}$ needs to be focused on in the general management of schizophrenic patients experiencing $\mathrm{AH}$ due to the strong association with QOL. The amount and intensity of distress as a result of the $\mathrm{AH}$ and the amount of negative content similarly need to be properly handled in patients' management for better emotional outcome. Other than pharmacological therapies to reduce positive symptoms which also include $\mathrm{AH}$, the role of psychological therapies such as acceptance, commitment therapy and mindfulness ${ }^{48,49}$ as well as group person-based cognitive therapy ${ }^{50}$ should also be carried out with special emphasis on addressing the specific $\mathrm{AH}$ dimensions as mentioned.

\section{ACKNOWLEDGEMENTS}

The research was partly funded by Universiti Kebangsaan Malaysia Medical Centre (UKMMC) grant: FF-2015-399.

\section{CONFLICT OF INTEREST}

None 


\section{REFERENCES}

1. Wyatt RJ, Henter I, Leary MC, Taylor E. An economic evaluation of schizophrenia-1991. Soc Psychiatry Psychiatr Epidemiol 1995;30:196-205.

2. Uhlhass PJ \& Mishara AL. Perceptual anomalies in schizophrenia: integrating phenomenology and cognitive neuroscience. Schizophr Bull 2006;33:142-156.

3. Waters F. Auditory hallucinations in psychiatric illness. Psychiatric Times 2010; 27:54-8.

4. Thomas P, Mathur P, Gottesman I, et al. Correlates of hallucinations in schizophrenia: A cross-cultural evaluation. Schizophr Res 2007;92:41-9.

5. Wahab A, Alaudin N, Wahab S, et al. The Hyperactivity of Efferent Auditory System in Patients with Schizophrenia: A Transient Evoked Otoacoustic Emissions Study. Psychiatry Invest. 2016;13:82-8.

6. Copolov DL, Mackinnon A, \& Trauer, T. Correlates of the affective impact of auditory hallucinations in psychotic disorders. Schizophr Bull 2004;30:163-171.

7. Beavan V \& Read J. Hearing voices and listening to what they say: the importance of voice content in understanding and working with distressing voices. J Nerv Ment Dis 2010; 198: 201-5.

8. Daalman K, Boks MP, Diederen KM et al. The same or different? A phenomenological comparison of auditory verbal hallucinations in healthy and psychotic individuals. J. Clin. Psychiatry 2011;72:320-325.

9. Harkavy-Friedman JM, Kimhy D, Nelson EA, et al. Suicide attempts in schizophrenia: the role of command auditory hallucinations for suicide. J Clin Psychiatry 2003;64:871-4.

10. Razali SM, Abd Wahid M. Quality of life and depressive symptoms in patients with schizophrenia. International Medical Journal 2012; 19:130-4.

11. Mubarak AR, Baba I, Chin LH, Hoe QS. Quality of life of community-based chronic schizophrenia patients in Penang, Malaysia. Aust N Z J Psychiatry 2003; 37:577-85.

12. Heider D, Angermeyer MC, Winkler I, et al. A prospective study of Quality of life in schizophrenia in three European countries. Schizophr Res 2007; 93:194-202.

13. Ertekin H, Er M, Ozayhan HY, et al. Quality of life and depression in schizophrenia patients living in a nursing home. Düşünen Adam. 2015; 28: 213-221.

14. Kay SR, Opler LA, Lindenmayer JP. The Positive and Negative Syndrome Scale (PANSS): rationale and standardisation. Br J Psychiatry Supplement. 1989;155:59-67.

15. Haddock G, McCarron J, Tarrier N, Faragher EB: Scales to measure dimensions of hallucinations and delusions: the psychotic symptom rating scales (PSYRATS). Psychol Med 1999; 29:879889.
16. Leucht S, Kane JM, Kissling W, et al. Clinical implications of Brief Psychiatric Rating Scale scores. Br J Psychiatry 2005;187:366-371.

17. Steel C, Garety PA, Freeman D, et al. The multidimensional measurement of the positive symptoms of psychosis. Int J Methods Psychiatr Res. 2007;16:88-96.

18. Sheehan DV, Lecruibiery $\mathrm{Y}$, Sheehan $\mathrm{KH}$, et al. The Mini-International Neuropsychiatric Interview (M.I.N.I.): The development and validation of a Structured Diagnostic Psychiatric Interview for DSM-IV and ICD-10. J Clin Psychiatry 1998;59:22-33.

19. Overall JE, \& Gorham D R. The brief psychiatric rating scale: Recent developments in ascertainment and scaling. Psychopharmacological Bulletin 2008:24:97-99.

20. Wahab S, Zakaria MN, Sidek D, et al. Evaluation of auditory hallucinations in patients with schizophrenia: A validation study of the Malay version of Psychotic Symptom Rating Scales (PSYRATS). Psychiatry Res 2015;228:462-7.

21. Addington D, Addington J, Maticka-Tyndale E. Assessing depression in schizophrenia: the Calgary Depression Scale. Br J Psychiatry Suppl 1993;22:39-44.

22. Addington $\mathrm{D}$, Addington J, Maticka-tyndale E, Joyce J: Reliability and Validity of a Depression Rating Scale for Schizophrenics. Schizophr Res 1992;6:201-8.

23. The WHOQOL Group. Development of the World Health Organization WHOQOL-BREF Quality of Life Assessment. Psychol Med 1998;28:551-58.

24. Hasanah $\mathrm{Cl}$, Naing L, Rahman ARA. World Health Organization Quality of Life Assessment: Brief Version in Bahasa Malaysia. Medical Journal of Malaysia 2003; 58:79-88.

25. Hafner H, Maurer K, Loffler W, et al. The epidemiology of early schizophrenia. Influence of age and gender on onset and early course. $\mathrm{Br}$ J Psychiatry1994;23(Supp.):29-38.

26. Proctor J (2000). Auditory hallucinations and the presence of depression in chronic schizophrenia patients. Retrieved from http://ro.ecu.edu.au/theses/1377.

27. Reine G, Lmcon C. Di Tucci S, Sapin C, Auquier $P$. Depression and subjective quality of life in chronic phase schizophrenic patients. Acta Psychiatr Scand 2003;108:297-303.

28. Xiang YT, Weng YZ, Leung CM, Tang WK, Ungvari GS. Quality of life of Chinese schizophrenia outpatients in Hong Kong: relationship to socio-demographic factors and symptomatology. Aust N Z J Psychiatry 2007;41:442-449.

29. Hsiao CY, Hsieh MH, Tseng CJ, Chien SH, Chang CC. Quality of life of individuals with schizophrenia living in the community: relationship to socio-demographic, clinical and psychosocial characteristics. J Clin Nurs. 2012; 21:2367-76.

30. Adewuya AO, Makanjuola ROA. Subjective quality of life of Nigerian schizophrenia 
patients: sociodemographic and clinical correlates. Acta Psychiatr Scand 2009; 120: 160-164.

31. Alshowkan A, Curtis J, White Y. Quality of life for people with schizophrenia: a literature review. The Arab Journal of Psychiatry 2012; 23:122-131.

32. Duke PJ; Pantelis C; Barnes TRE. South Westminster schizophrenia survey: Alcohol use and its relationship to symptoms, tardive dyskinesia and illness onset $\mathrm{Br} \mathrm{J}$ Psychiatry 1994; 164:630-6.

33. Hambrecht $M$, Hafner $H$. Substance abuse and the onset of schizophrenia. Biol Psychiatry 1996;40:1155-63.

34. Conley RR, Buchanan RW. Evaluation of treatment-resistant schizophrenia. Schizophr Bull 1997;23:663-74.

35. Elkis H. History and current definitions of treatment-resistant schizophrenia. TherapyResistant Schizophrenia 2010; 26:1-8. Karger Publishers.

36. Birchwood $M$, \& Chadwick P. The omnipotence of voices: testing the validity of a cognitive model. Psychol Med 1997;27:1345-53.

37. Soppitt RW \& Birchwood M. Depression, beliefs, voice content and topography: a cross-sectional study of schizophrenic patients with auditory verbal hallucinations. Journal of Mental Health 1997;6:525-32.

38. Caron J, Lecomte Y, Stip E, Renaud S. Predictors of quality of life in schizophrenia. Community Ment Health J. 2005; 41:399-417.

39. Eack SM, Newhill CE. Psychiatric symptoms and quality of life in schizophrenia: a metaanalysis. Schizophr Bull 2007; 33: 1225-37.

40. Priebe $S, M c C a b e ~ R$, Junghan $U$, et al. Association between symptoms and quality of life in patients with schizophrenia: A pooled analysis of changes over time. Schizophr. Res 2011; 133:17-21.

41. Browne S, Roe M, Lane A, et al. Quality of life in schizophrenia: Relationship to sociodemographic factors, symptomatology and tardive dyskinesia. Acta Psychiatr Scand 1996;94:118-24.

42. Karow A, Moritz S, Lambert M, Schoder S, Krausz M. PANSS syndromes and quality of life in schizophrenia. Psychopathology 2005;38:3206.

43. Narvaez JM, Twamley EW, McKibbin CL, Heaton RK, Patterson TL. Subjective and objective quality of life in schizophrenia. Schizophr Res 2008;98:201-8.

44. Ritsner M, Modai I, Endicott J et al. Differences in quality of life domains and psychopathologic and psychosocial factors in psychiatric patients. J Clin Psychiatry 2000; 61:880-9.

45. Hoffmann H, Kupper Z, \& Kunz B. Hopelessness and its impact on rehabilitation outcome in schizophrenia- an exploratory study. Schizophr Res 2000;16:147-158.

46. Lecomte Y, Caron J, Stip E, \& Renaud S. Exploratory study on adaptation of people with schizophrenia. Schizophr Res 2004;72:283-5.

47. Dominic F, Peter H, Neil T, Nicola G, Simon S, Til W. The self or the voice? Relative contributions of self-esteem and voice appraisal in persistent auditory hallucinations. Schizophr Res 2009; 112:174-180

48. Gaudiano BA, Herbert JD. Acute treatment of inpatients with psychotic symptoms using Acceptance and Commitment Therapy: pilot results. Behav Res Ther 2006;44:415-437.

49. Khoury B, Lecomte T, Gaudiano BA, Paquin K. M indfulness interventions for psychosis: a metaanalysis. Schizophr Res 2013;150:176-184.

50. Dannahy L, Hayward M, Strauss C, et al. Group person-based cognitive therapy for distressing voices: pilot data from nine groups. J Behav Ther Exp Psychiatry. 2011;42:111-6. 